\title{
Separability Analysis of Back-Scattering Coefficient of NovaSAR-1 S-band SAR datasets for different Land Use Land Cover (LULC) classes
}

Ashutosh Bhardwaj ( $\sim$ ashutosh@iirs.gov.in )

Indian Institute of Remote Sensing https://orcid.org/0000-0002-9241-5427

Ojasvi Saini

Indian Institute of Remote Sensing

R. S. Chatterjee

Indian Institute of Remote Sensing

\section{Research Article}

Keywords: NovaSAR-1, S-band, HH polarization, LULC, radar backscattering coefficient

Posted Date: September 8th, 2021

DOl: https://doi.org/10.21203/rs.3.rs-854337/v1

License: (c) (i) This work is licensed under a Creative Commons Attribution 4.0 International License.

Read Full License 


\section{Abstract}

NovaSAR-1 is a joint technology initiative of SSTL (Surrey Satellite Technology Ltd.), UK, and Airbus DS (former EADS Astrium Ltd, Stevenage, UK). The NovaSAR-1 mini-satellite was launched on 16 September 2018 and it is operating on the S-band frequency range, which is less common in Spaceborne Synthetic Aperture Radar (SAR) systems. Both higher and lower SAR frequency bands (L-band \& X-band SAR) have their advantages as well as limitations in different kinds of applications. High frequency (X-band) SAR systems are useful for top surface information extraction such as the DSM generation. However, at the same time, more noise and lesser coherence issues are associated with high-frequency SAR systems. Low-frequency SAR (L-band) systems exhibit better ground penetration, high coherence, and low noise, but less precise scatterer level information. The S-band comes approximately in the middle of the $X$ and L-band SAR frequency range and may be used as a trade-off between high and low-frequency SAR systems to have some advantages. In the presented study, the separability analysis of the radar backscattering coefficient of HH polarization (Stripmap and ScanSAR) of NovaSAR-1 S-band datasets corresponding to different land use and land covers (LULCS) has been done to analyze the potential of NovaSAR-1 S-band SAR data. The analysis was carried out for datasets acquired between 9th July 2019 to 15th July 2019 at 5 experimental sites in parts of six different Indian states (West Bengal, Maharashtra, Jharkhand, Odisha, Chhattisgarh, and Uttar Pradesh). The statistical analysis of o囚 for five different sites of India for different LULCs, such as bare soil, forest, water, urban, cropland, and road features has been carried out. The range for minimum and maximum mean $\sigma 囚$ values for urban, suburban, cropland, bare soil, barren land, forest, turbid water, road features, water with a smooth surface (calm water), and road features (airplane runway) were found to be -5.45 to $4.76,-11.14$ to $-5.21,-17.25$ to $-5.99,-18.15$ to $-13.44,-17.64$ to $-9.34,-17.17$ to $-14.34,-18.2$ to $-14.05,-27.29$ to -23.76 and -26.64 to -14.98 respectively. The range of $\sigma \otimes$ pixel values of calibrated datasets corresponding to different LULCs depicted that the data quality is good for the identification of various land covers. The separability analysis of the different land cover classes depicted that classes have good separability except for a few pairs of LULC. With the availability of fully polarimetric and InSAR data in the planned NISAR mission, the polarimetric scattering behaviour with phase information for InSAR will further be utilized.

\section{Introduction}

NovaSAR-1 is a very low-cost small SAR satellite. The mission key features and instrument specialism of the NovaSAR-1 satellite have been designed to make it suitable for a wide range of applications, such as forestry, disaster monitoring (particularly flooding), agriculture, and maritime observations (including ship and oil slick detection)[1]. Suitability of various applications of diverse kinds from low-resolution environmental observations to the thorough study of definite ground target areas demonstrates the potential of the NovaSAR-1 mission. The NovaSAR-1 mission has been developed with an applicationfocused approach based on medium resolution applications keeping in mind the fulfillment of user's needs in the most lucrative way [1]. This mission is a quite special and different spaceborne SAR mission from all other previous missions launched for earth's observation because its payload consists of an S- 
band SAR sensor, which is less common in spaceborne SAR systems [2], [3]. This mission is operating around $3.2 \mathrm{GHz}$ frequency which is near to the C-band and between the SAR frequencies of $\mathrm{X}$ - and Lband. Therefore, the S-band SAR system can be reasonably expected to serve a similarly wide range of applications to those demonstrated by systems currently operating in the C-band[4]. S-band SAR may be expected to serve as a trade-off between high and low-frequency SAR systems to overcome the limitations of both high and low-frequency SAR systems up to some extent[5]. For example it is found successful in detection of below-canopy inundation in floodplain forests due to the specular doublebounce scattering in the tropical forest and wetlands regions of the Amazon Basin [6], maritime Surveillance [7], [8], terrestrial and marine environments [9] and data association or fusion techniques for object identifications [10].

The radar backscattering coefficient $\sigma^{\circ}$ provides quantitative information about the back-scattered radiation from images surface features. It is a function of both sensor and ground parameters including radar frequency, polarisation, the incidence angle of the electromagnetic waves emitted, roughness, geometric shape, and dielectric properties of the target [11]. The scattering characteristics of different surface features vary according to their structural, and dielectric properties [12]. for example, due to the structural properties, urban and manmade features exhibit double-bounce scattering which makes the appearance of these features very bright in SAR images; forest area shows intermediate backscatter due to the mixed scattering from leaves, stems, ground, and branches; calm water (smooth surface) looks very dark (low backscatter) because of high dielectric constant and impenetrability properties; rough sea exhibits increased backscatter due to the ripples and water waves formed by wind current effects.

In all polarization channels of SAR signal, the back-scattering coefficient has a strong correlation with the geological parameters of particular land cover such as surface roughness and soil moisture content [13], which make it useful for geologists. Forest cover mapping, delineation of deforestation, and tree height estimation using SAR tomography are some of the applications related to the field of forestry. SAR helps in the strategic operational planning in emergency or disaster scenarios by observing ground movements even in bad weather and nighttime condition. SAR images are found to be very much suitable for the identification of sea objects because of the very bright appearance of sea objects in SAR images against the dark sea surface in the background[14].

Studies regarding the assessment of back-scattering characteristics of different space-borne and airborne SAR sensors operating in X, C, and L-band frequency range has already been carried out and providing useful information in several dimensions of applications namely agriculture, maritime surveillance, geological study, forestry, military, and homeland security, glaciology and many more with some advantages as well as disadvantages. Already operating SAR sensors in high and low-frequency domains are either advantageous or disadvantageous due to their high or low-frequency nature when used for certain specific applications. This study is important because it assesses the performance of Sband SAR which is expected to serve as a trade-off between high and low-frequency SAR systems to overcome the limitations of both high and low-frequency SAR systems up to some extent. In several previous studies, S-band exhibited better performance when compared with C- and X-band SAR. S-band 
backscatter was found to have high sensitivity to the forest canopy characteristics across all polarisations and incidence angles which establishes the usefulness of S-band SAR data in the field of forestry[15]. SAR signals at shorter wavelengths (C- and X-bands) are known to saturate rapidly with forest biomass due to lower canopy penetration. The microwave pulse primarily interacts with the foliage and smaller branches in the upper canopy layers at these wavelengths[16]. The results of a study of soil moisture retrieval for X-and S-band using the Integral Equation Model (IEM) applied through Artificial Neural Network (ANN) showed a very good performance in S-band in comparison with X-band[17].

The presented study includes a preliminary assessment of back-scattering characteristics of S-band SAR datasets. The separability analysis of the radar backscattering coefficient of NovaSAR-1 S-band (Stripmap and ScanSAR) HH polarization datasets corresponding to different LULCs of the Indian region

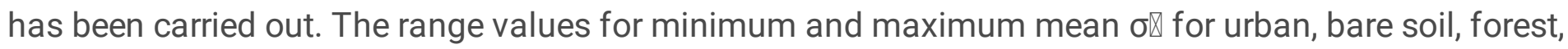
water, cropland, and road features were computed for separability analysis of different LULC. Three different parametric separability analysis methods namely Euclidean Distance, Transformed Divergence and Jefferies-Matusita have been carried out for the separability analysis of different LULC classes of experimental sites.

\section{Experimental Sites And Data Sources}

The five different data swaths of NovaSAR-1 with Stripmap (6 m ground resolution) and ScanSAR (20 m ground resolution) modes were acquired in $\mathrm{HH}$ polarization over six different Indian states (West Bengal, Maharashtra, Jharkhand, Odisha, Chhattisgarh, and Uttar Pradesh) as shown in Fig.1 have been studied

for the separability analysis of radar back-scattering coefficient of different LULC. The experimental sites include urban areas (such as Kolkata and Ranchi city), forest areas, Crop Land, water bodies, barren land, and bare soil land covers. The data properties (such as operational mode, polarization, resolution, and calibration constant) of the different NovaSAR-1 datasets acquired for different experimental sites are shown in table 1.

\subsection{West Bengal (Kolkata site and nearby region)}

Kolkata is located along the banks of the Hooghly River in the eastern part of India. The study area covers a latitude range of $22^{\circ} 24^{\prime} 45.14^{\prime \prime} \mathrm{N}$ to $23^{\circ} 2^{\prime} 11.89^{\prime \prime} \mathrm{N}$ and longitude range of $88^{\circ} 12^{\prime} 35.10^{\prime \prime} \mathrm{E}$ to $88^{\circ} 33^{\prime} 28.21^{\prime \prime E}$. Kolkata has a tropical wet-and-dry climate, with summer monsoons. The climate of the region is humid during summer and pleasant in winter. According to Kolkata municipality, the average rainfall in Kolkata is 1400-1600 mm per year. The Kolkata Municipal area covers an extent of $206.08 \mathrm{sq}$. $\mathrm{km}[18][19]$. The soil and water are mainly alluvial in origin in this region. Quaternary sediments comprising clay and silt, together with various grades of sand and gravel, underlie the region[20].

\subsection{Maharashtra Site}

The study area covers part of Maharashtra state with a latitude range of $17^{\circ} 08^{\prime} 12.56^{\prime \prime} \mathrm{N}$ to $17^{\circ} 44^{\prime} 36.91^{\prime \prime}$ $\mathrm{N}$ and longitude range of $73^{\circ} 36^{\prime} 37.66^{\prime \prime} \mathrm{E}$ to $73^{\circ} 37^{\prime} 34.36^{\prime \prime} \mathrm{E}$. The entire area of the state consists of rocks 
that originated from considerable metamorphism of the most primordial rocks of miscellaneous origin[21]. The study area comprises the forest areas, Crop Land, water bodies, barren land, and bare soil land covers. Most of the part of the image is hilly and mountainous consisting of Deccan plate comprises a huge accumulation of volcanic rocks.

\subsection{Jharkhand site}

The image for the study site covers Ranchi city (capital of Jharkhand) and the north-eastern neighboring area of the city. The study area covers latitude range of $23^{\circ} 18^{\prime} 26.52^{\prime \prime} \mathrm{N}$ to $23^{\circ} 43^{\prime} 23.69^{\prime \prime} \mathrm{N}$ and longitude range of $85^{\circ} 20^{\prime} 5.70^{\prime \prime} \mathrm{E}$ to $85^{\circ} 22^{\prime} 25.50^{\prime \prime} \mathrm{E}$. The northernmost and southernmost parts of the image are covered with hillocks and forests. The Ranchi district is part of the Chotanagpur plateau and consists of the soils, most of the residual type.

\subsection{Chhattisgarh, Jharkhand, Odisha \& Uttar Pradesh site}

The image for this study site covers part of four states namely Chhattisgarh, Jharkhand, Odisha, and Uttar Pradesh. Out of these states, the image footprint majorly covers Chhattisgarh and Odisha states. The study area covers a latitude range of $20^{\circ} 8^{\prime} 43.411^{\prime \prime} \mathrm{N}$ to $24^{\circ} 8^{\prime} 32.89 " \mathrm{~N}$ and longitude range of $82^{\circ} 53^{\prime} 4.88^{\prime \prime} \mathrm{E}$ to $84^{\circ} 39^{\prime} 38.18^{\prime \prime} \mathrm{E}$. The study area consists of hilly and plain terrain with forest, Crop, water bodies, barren land, and bare soil land covers.

\section{Methodology}

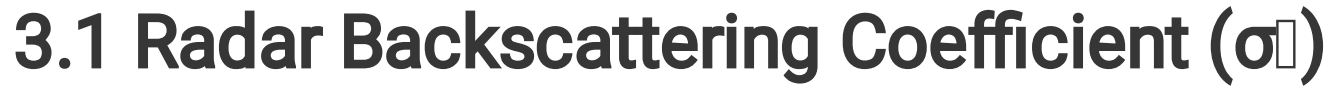

The radar backscattering coefficient $\sigma^{\circ}$ provides quantitative information about the back-scattered radiation from images surface features. It is a function of both sensor and ground parameters including radar frequency, polarisation, the incidence angle of the electromagnetic waves emitted, roughness, geometric shape, and dielectric properties of the target [11].

The five different data swaths of NovaSAR-1 with Stripmap ( $6 \mathrm{~m}$ ground resolution) and ScanSAR (20 m ground resolution) modes were acquired in $\mathrm{HH}$ polarization over the experimental sites (West Bengal, Maharashtra, Jharkhand, Odisha, Chhattisgarh, and Uttar Pradesh) in India were processed according to the methodology given in flowchart Fig. 2. The NovaSAR-1 datasets were analyzed and visually interpreted in SNAP software using a SNAP plugin named "NovaSAR Product Reader". The backscattering coefficient $(\sigma \square)$ for each of the images was generated using Eq. (1) described in an Airbus technical report[15].

$$
\sigma^{\circ}=10 \log 10(\mathrm{DN} 2)-\mathrm{K}_{\mathrm{cal}}
$$


Where $\sigma \mathbb{Q}$ is the back-scattering coefficient, $\mathrm{DN}$ represents pixel value in amplitude image and $\mathrm{K}_{\text {cal }}$

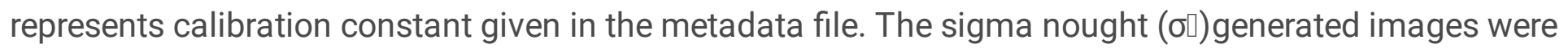
filtered using Median filter (window size 7X7) to reduce the speckle effect inherent in the SAR images. Region of interest (ROI) samples for different LULCs were selected from the filtered sigma nought images for the separability analysis of back-scattered pixel values for different land covers such as urban, bare soil, forest, water, cropland, and road features. The SAR image view and corresponding natural RGB view of different LULC classes of experimental sites are shown in figure 3 and 4 . The ROI samples for different LULC classes were used for the statistics generation and separability analysis of the LULC classes. Three different parametric separability analysis methods namely Euclidean Distance, Transformed Divergence and Jefferies-Matusita have been carried out for the separability analysis of different LULC classes of experimental sites.

\section{Results And Discussion}

In the case of the West Bengal-1 (Kolkata) site, the mean $\sigma \nabla$ value was found to be positive (3.84 $\mathrm{dB})$ for the urban built-up class, which can be attributed to strong double bounce. All the remaining other classes depicted negative mean o\values for this site as shown in figure 5. All the LULC classes depicted negative mean $\sigma \rrbracket$ values for Maharashtra site, with the Urban built-up class exhibiting the highest mean $\sigma \bigotimes$ value $(-3.23 \mathrm{~dB})$. The smooth water surface class has a minimum mean $\sigma \nabla$ value of $-26.9 \mathrm{~dB}$ at Maharashtra site as shown in figure 6.

At the Chhattisgarh site, the urban built-up class exhibited the highest mean $\sigma \nabla$ value $(-5.45 \mathrm{~dB})$. In this image, two different types of signatures were found for water bodies. The signature of turbid water with mean $\sigma \nabla$ value - $14.05 \mathrm{~dB}$ was brighter than the signature of smooth water surface with mean $\sigma \nabla$ value $27.29 \mathrm{~dB}$ as shown in Fig. 7. The samples of water bodies of both the water classes are shown in Figs. 3 and 4. In the case of Jharkhand, Ranchi Site, the urban built-up class is the only class exhibiting positive mean $\sigma \otimes$ value $(4.76 \mathrm{~dB})$ among the all other LULC at R Ranchi Site. The turbid water class is showing -

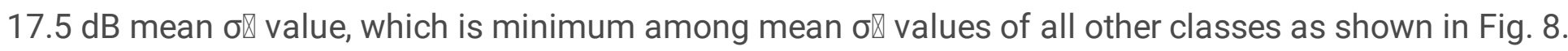

The mean sigma nought statistics of West Bengal-2 site is shown by the graph in figure 9 . The urban builtup land cover class is exhibiting a maximum mean sigma nought value of $-2.34 \mathrm{~dB}$. All the classes of this site exhibit fairly separated mean sigma nought values as shown in figure 9 . The minimum to maximum mean sigma nought range values of all the LULC classes of all five experimental sites is shown by the graph in figure 10 .

\subsection{Comparative Mean olAnalysis of Different Land-Covers for Different Experimental sites}

The plot of the mean $\sigma \rrbracket$ value for each class in all the experimental sites has also been generated for the comparative analysis of the back-scatter behaviour of each class in every experimental site. In all the experimental sites smooth water surface class is showing the minimum mean $\sigma \rrbracket$ value and the urban

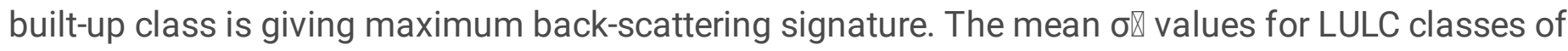


Jharkhand site are comparatively higher than the mean $\sigma \otimes$ values for other experimental sites as clearly visible in Fig. 11.

\subsection{Separability Analysis of Different LULC Classes Using NovaSAR-1 Sigma Nought Images}

The range of mean $\sigma \otimes$ values of Calibrated datasets corresponding to different LULCs depicted that the data quality is good for the identification of various land covers. The separability analysis of the different land cover classes depicted that some pairs of classes have good separability than others. Euclidean Distance, Transformed Divergence and Jefferies-Matusita separability analysis methods were used to analyse the separability between LULC class pairs. Transformed Divergence and Jefferies-Matusita separability analysis methods are giving better separability results than Euclidean Distance method. Figures 12,13 and 14 are depicting the separability of LULC classes of experimental site (Kolkata, West Bengal-1) using Euclidean Distance, Transformed Divergence and Jefferies-Matusita separability analysis methods respectively. A transformed divergence value of 2000 suggests an excellent separation between classes. Above 1900 provides good separation, while below 1700 is poor. The separability analysis of the different LULC classes depicted that classes have good separability except for pairs namely bare soil, and barren land; cropland and bare soil; waterbody smooth and road feature; water body turbid and bare soil; water body turbid and barren land, as shown in Fig. 13.

Larger size ROls were chosen for the boxplot analysis. Boxplot represents the sigma nought distribution of different LULC classes of different experimental sites as shown in Figs. 15, 16, 17 and 18. Overlapping of sigma nought distribution of different LULC classes can be analyzed using boxplot graphs and the presence of outliers depicts the inherent property of speckling in SAR data.

\section{Conclusions}

Range of $\sigma \otimes$ pixel values of Calibrated NovaSAR-1 S-band HH polarization datasets corresponding to different LULCs depicted that the data quality is good for the identification of various land use and land cover classes, as depicted in the separability analysis. As two different signatures of the water body were found in the back-scattering ( $\sigma \square$ images) data analysis, the NovaSAR-1 S-band HH polarization data is highly sensitive to the roughness of the water surface. The texture information of the targets was found discernible in $6 \mathrm{~m}$ spatial resolution datasets. The separability analysis of the different LULC classes depicted that classes have good separability except for a few pairs of LULC classes as discussed in the results. With the availability of fully polarimetric as well as single look complex (SLC) interferometric data in the future, the polarimetric scattering behavior and phase information along with the interferometric performance of the data may be analyzed. The quality of datasets was also found good for its locational accuracy. The datasets were also suitable for topographic interpretation using layover, foreshortening, and shadow effects in the images besides the separability analysis carried out in the study.

\section{Declarations}




\section{Funding}

The study was funded by Indian Space Research Organization (ISRO) under the NASA-ISRO SAR (NISAR) L \& S Airborne SAR project scheme.

\section{Acknowledgment}

Authors would like to thank SSTL (Surrey Satellite Technology Ltd.), UK, Airbus DS (former EADS Astrium Ltd, Stevenage, UK) and Indian Space Research Organization (ISRO) for their insights and support through data-sharing platforms.

\section{Competing interests}

The authors declare no competing interests

\section{References}

1. Bird, R., Whittaker, P., Stern, B., Angli, N., Cohen, M., \& Guida, R. "NovaSAR-S: A low cost approach to SAR applications," Conf. Proc. 2013 Asia-Pacific Conf. Synth. Aperture Radar, APSAR 2013, pp. 8487(2013).

2. Iervolino, P., Guida, R., \& Whittaker, P. “Novasar-S and maritime surveillance," Int. Geosci. Remote Sens. Symp., pp. 1282-1285(2013). doi: 10.1109/IGARSS.2013.6723015.

3. Rossi, C., Bayaraa, M., Jones, T., Minchella, A., \& Agass, S. "The NovaSAR UK Background Mission," in IGRASS 2019(2019). pp. 8396-8399.

4. Natale, A., Guida, R., Bird, R., Whittaker, P., Cohen, M., \& Hall, D. "Demonstration and analysis of the applications of S-band SAR,"(2011). 3rd Int. Asia-Pacific Conf. Synth. Aperture Radar, APSAR 2011, pp. 167-170, 2011.

5. Saini, O., Bhardwaj, A., \& Chatterjee, R. S. "Analysis of Back-Scattering Coefficient of NovaSAR-1 SBand SAR," in National Seminar on Recent Advances in Geospatial Technology and Application(2018). pp. 1-7.

6. Rosenqvist, A., Parker, A., Zhou, Z., Brindle, L., \& Held, A. “First Assessment of NovaSAR-1 S-band SAR Backscatter Characteristics over Tropical Wetlands," in IGRASS 2020(2020). pp. 5065-5068, [Online]. Available: https://ieeexplore.ieee.org/stamp/stamp.jsp?tp=\&arnumber=9324143.

7. Achiri, L., Guida, R., \& lervolino, P. “Collaborative use of SAR and AIS data from NovaSAR-S for Maritime Surveillance,”(2018). [Online]. Available: https://www.vde-verlag.de/proceedingsen/454636253.html.

8. Vicente, R., Tabanggay, L., Rayo, J., Mina, K., \& Retamar, A. “Earth observation applications for goal 14: Improving maritime domain awareness using synthetic aperture radar imaging with automatic 
identification system in the philippines," Int. Arch. Photogramm. Remote Sens. Spat. Inf. Sci. - ISPRS Arch., vol. 43, no. B3, pp. 215-219, Aug(2020). doi: 10.5194/ISPRS-ARCHIVES-XLIII-B3-2020-2152020.

9. Parker, A., Zhou, Z. S., Held, A., Brindle, L., \& Rosenqvist, A. “New Insights from Australia's Synthetic Aperture Radar Capability, NOVASAR-I," in IGARSS 2020-2020 IEEE International Geoscience and Remote Sensing Symposium(2020). pp. 5971-5973, doi: 10.1109/IGARSS39084.2020.9324248.

10. Rodger, M., \& Guida, R. "Data Association Techniques for Near-Contemporaneous SAR and AIS Datasets from NovaSAR-1," in IGARSS 2019-2019 IEEE International Geoscience and Remote Sensing Symposium(2019). pp. 700-703, doi: 10.1109/IGARSS.2019.8898207.

11. Barrett, B. W., Dwyer, E., \& Whelan, P. "Soil moisture retrieval from active spaceborne microwave observations: An evaluation of current techniques," Remote Sens., vol. 1, no. 3, pp. 210-242, $\operatorname{Sep}(2009)$. doi: 10.3390/rs1030210.

12. Navalgund, R. R., Senthil kumar, A., \& Nandy, S. (2019). Remote sensing of northwest Himalayan ecosystems. Springer

13. Mohy, H., El-Magd, I. A., Basta, F., \& Amasha, A. "Utilization of full-polarimetric SAR data (RADARSAT2), ASTER and Landsat 8 data in geological mapping of the west Gebal Elba area, Halayeb district, South Eastern Desert, Egypt," J. Indian Soc. Remote Sens., vol. 47, no. 2, pp. 267-278, Feb(2019). doi: 10.1007/s12524-018-0923-7.

14. Saini, O., Bhardwaj, A., \& Chatterjee, R. S. "Ship Detection from RISAT-1 and Radarsat-2 SAR Images using CFAR," in MOL2NET, International Conference Series on Multidisciplinary Sciences USEDAT-08: USA-Europe Data Analysis Training Program Workshop, UPV/EHU, Bilbao-MDC, Miami, USA, 2020(2020). p. 8.

15. Ningthoujam, R., et al. (Jul. 2016). Airborne S-Band SAR for Forest Biophysical Retrieval in Temperate Mixed Forests of the UK. Remote Sens, 8(no. 7), 609. doi: 10.3390/rs8070609.

16. Mayaux, P., De Grandi, G. F., Rauste, Y., Simard, M., \& Saatchi, S. "Large-scale vegetation maps derived from the combined L-band GRFM and C-band CAMP wide area radar mosaics of Central Africa," Int. J. Remote Sens., vol. 23, no. 7, pp. 1261-1282, Apr(2002). doi: 10.1080/01431160110092894.

17. Guida, R., \& Fotias, V. "Soil moisture retrieval with S-band SAR data," in International Geoscience and Remote Sensing Symposium (IGARSS), Nov(2015). vol. 2015-Novem, pp. 1304-1307, doi: 10.1109/IGARSS.2015.7326014.

18. "Official Website of Kolkata Municipal Corporation." https://www.kmcgov.in/KMCPortal/jsp/BasicStatistics.jsp(accessed Jul.22,

19. Diptendra, D., \& Chattopadhyay, B. C. (2009). "Characterization of Soil over Kolkata Municipal Area. Bengal: " Howrah

20. Bunting, S. W., Kundu, N., \& Mukherjee, M. "Situation analysis of production systems and natural resource use in PU Kolkata,"(2002). 
21. "Directorate of Geology and Mining \& Maharashtra, G. (accessed Jun. 12, 2020). Nagpur." https://mahadgm.gov.in/InternalPage.aspx?

Antispam=0lv3xq8MYjW\&Minerallnforma\%0AtionID=1\&MyAntispam=4fujaGqzqci

\section{Table 1}

Table 1. Properties of NovaSAR-1 datasets used for different experimental sites

\begin{tabular}{|c|c|c|c|c|c|}
\hline $\begin{array}{c}\text { Data } \\
\text { Properties }\end{array}$ & Maharashtra & West Bengal & West Bengal-2 & Chhattisgarh \& Odisha & Ranchi, Jharkhand \\
\hline Product & $\begin{array}{c}\text { NovaSAR_01_6656_grd } \\
\text { _190709_175159_HH }\end{array}$ & $\begin{array}{c}\text { NovaSAR_01_6662_grd } \\
\text { 190710_042922_HH }\end{array}$ & $\begin{array}{c}\text { NovaSAR_01_6720_grd } \\
\text { _190713_163738_HH }\end{array}$ & $\begin{array}{c}\text { NovaSAR_01_6715_scd } \\
\text { 190713_044610_HH }\end{array}$ & $\begin{array}{c}\text { NovaSAR_01_6737_grd } \\
\text { _190715_164900_HH }\end{array}$ \\
\hline $\begin{array}{l}\text { Operational } \\
\text { Mode }\end{array}$ & 6m_Stripmap_HH_5 & 6m_Stripmap_HH_F8 & 6m_Stripmap_HH_G2 & $20 \mathrm{~m}$ _ScanSAR_HH_H1- & 6m_Stripmap_HH_G5 \\
\hline Polarization & $\mathrm{HH}$ & $\mathrm{HH}$ & $\mathrm{HH}$ & $\mathrm{HH}$ & $\mathrm{HH}$ \\
\hline $\begin{array}{l}\text { Product } \\
\text { Type }\end{array}$ & GRD & GRD & GRD & SCD & GRD \\
\hline Pass & Descending & Ascending & Descending & Ascending & Descending \\
\hline $\begin{array}{l}\text { Antenna } \\
\text { Pointing }\end{array}$ & Left & Right & Right & Right & Right \\
\hline $\begin{array}{c}\text { Range } \\
\text { Resolution }\end{array}$ & $5.90 \mathrm{~m}$ & $5.83 \mathrm{~m}$ & 5.79 & $18.28 \mathrm{~m}$ & $5.91 \mathrm{~m}$ \\
\hline $\begin{array}{c}\text { Azimuth } \\
\text { Resolution } \\
\text { Calibration }\end{array}$ & $6.04 \mathrm{~m}$ & $6.04 \mathrm{~m}$ & 6.04 & $19.83 \mathrm{~m}$ & $6.04 \mathrm{~m}$ \\
\hline $\begin{array}{l}\text { Constant } \\
\text { (Linear } \\
\text { scale) }\end{array}$ & $7.98 \mathrm{E}+05$ & $7.98 \mathrm{E}+05$ & $7.98 \mathrm{E}+05$ & $3.99 \mathrm{E}+06$ & $1 \mathrm{E}+05$ \\
\hline
\end{tabular}

\section{Figures}



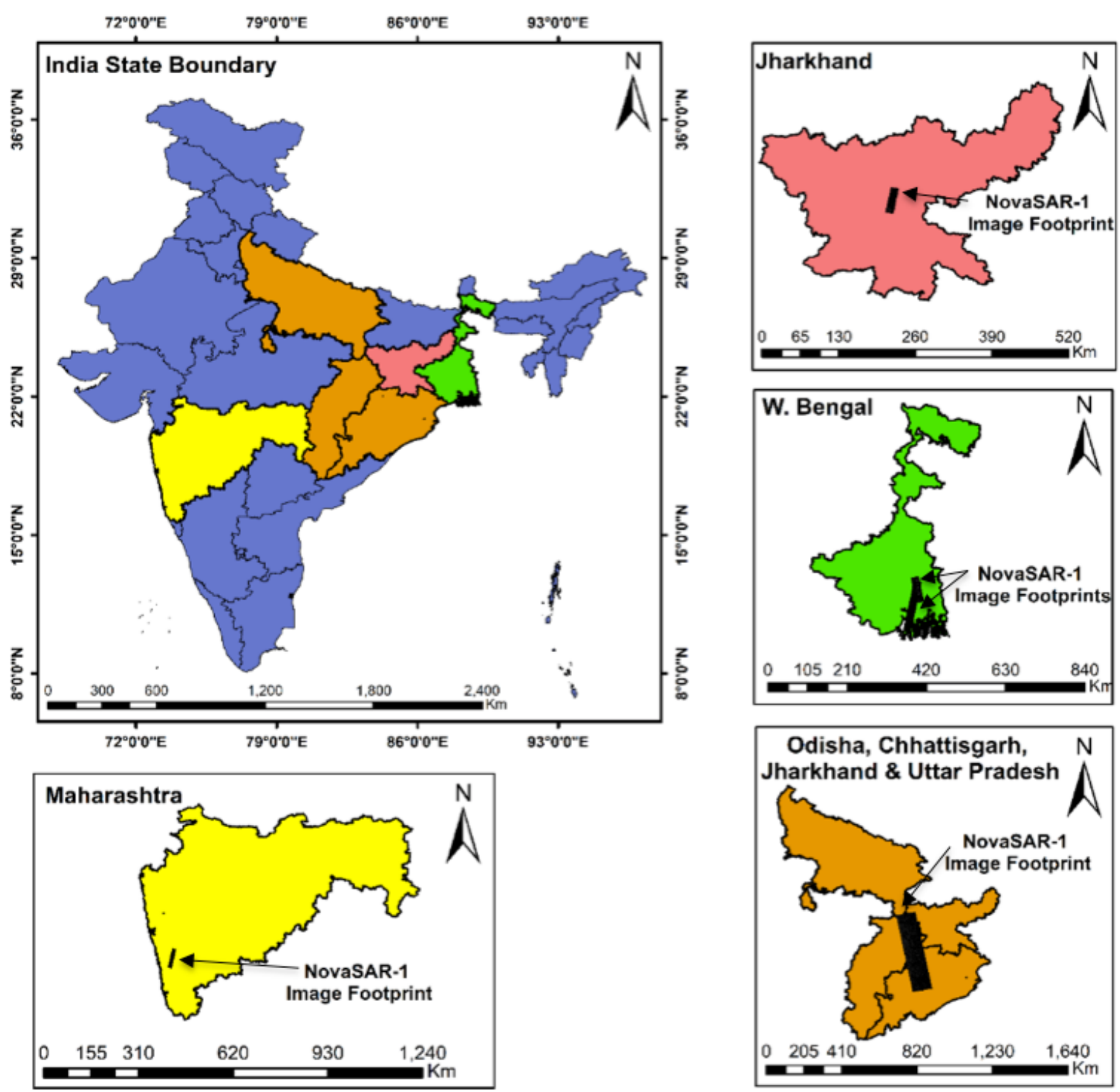

Figure 1

Locations for NovaSAR-1 Swaths over different experimental sites in India. 


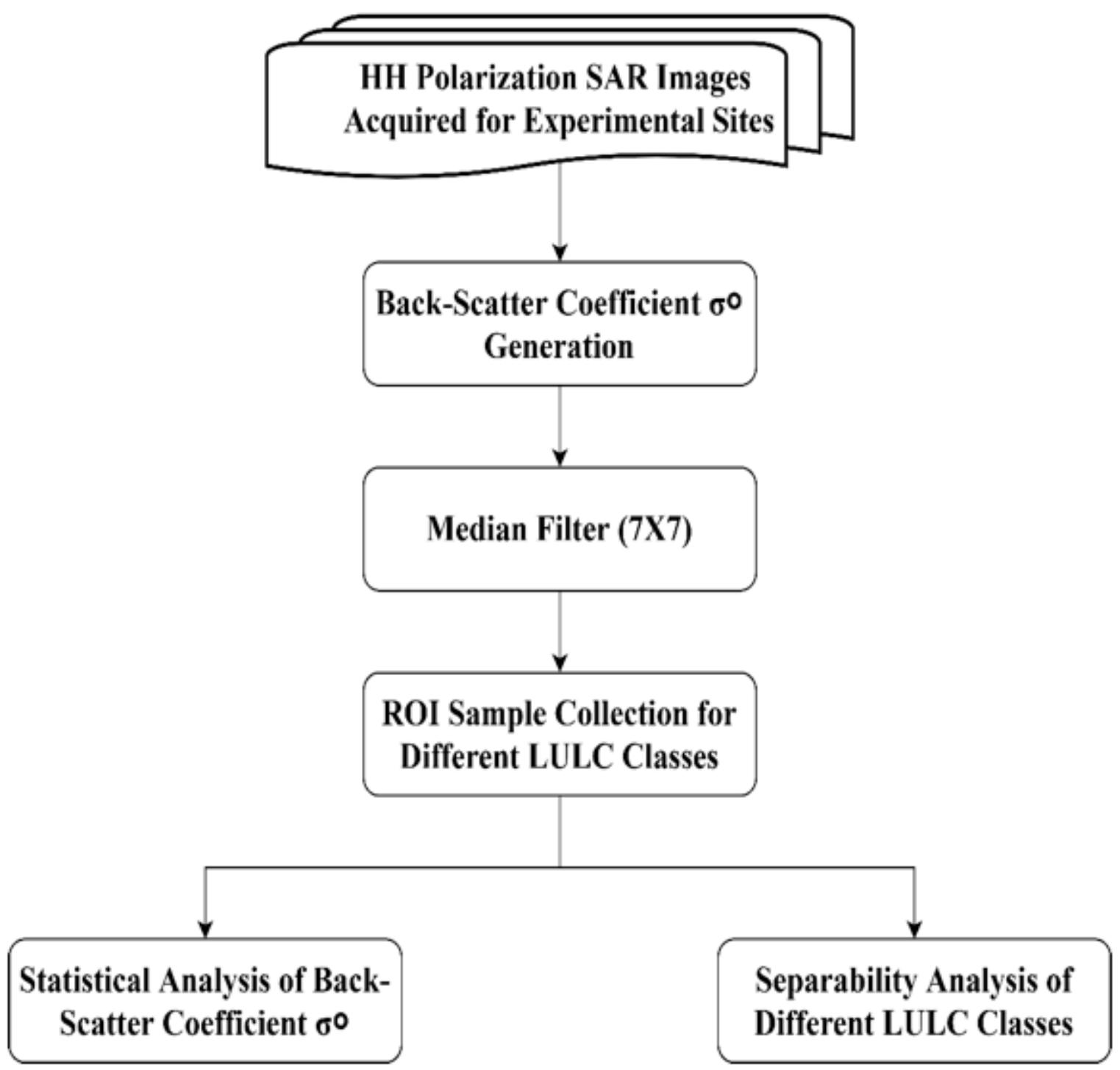

Figure 2

Flowchart of the methodology adopted in the study. 


\section{Chhattisgarh Site Maharashtra Site West Bengal Site Jharkhand Site}

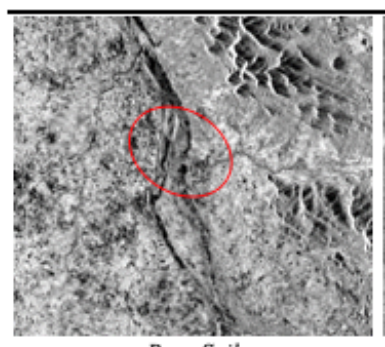

Bare Soil

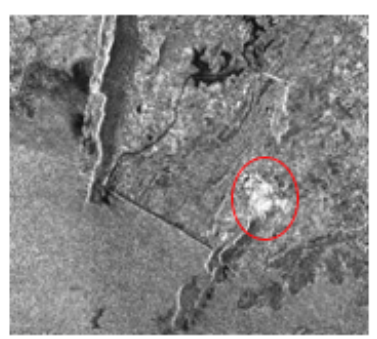

Urban Built-up

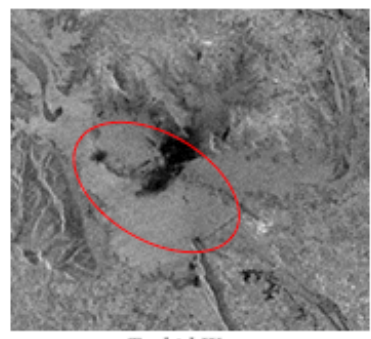

Turbid Water

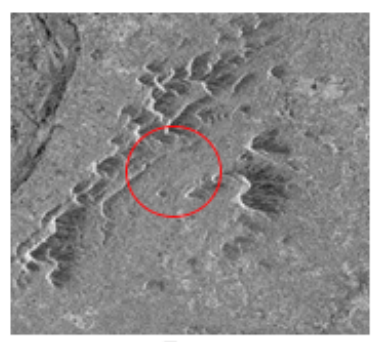

Forest

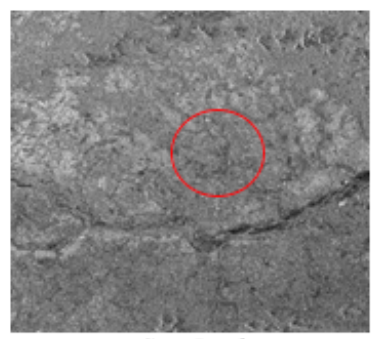

Crop Land

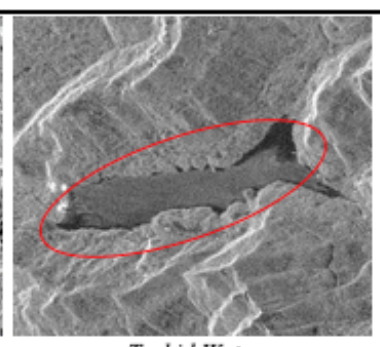

Turbid Water

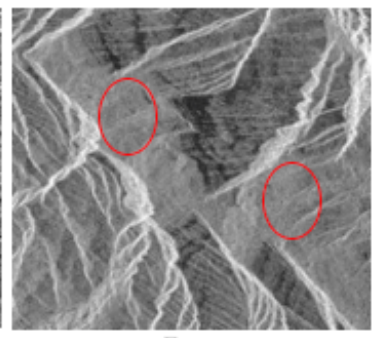

Forest

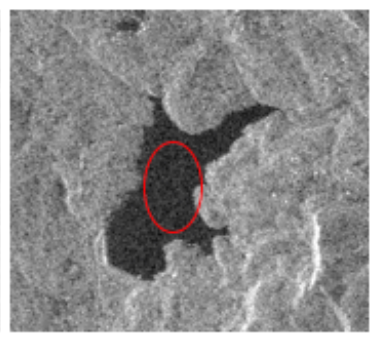

Smooth Water Surface

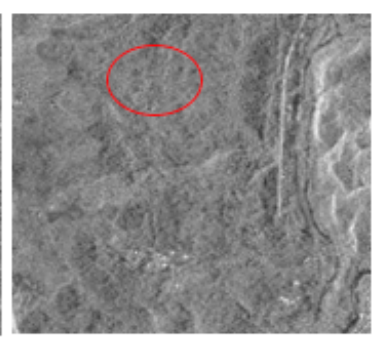

Crop Land

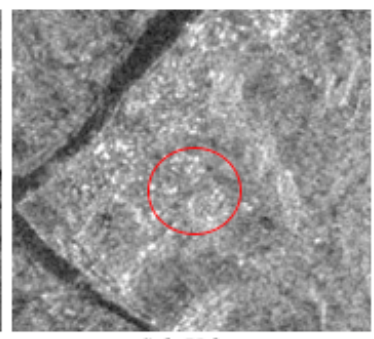

Sub-Urban

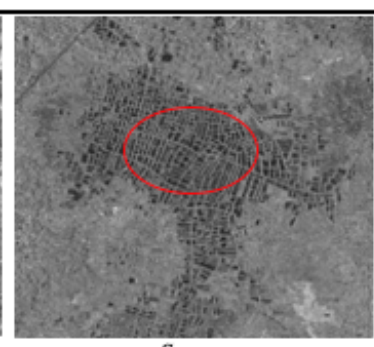

Swamp

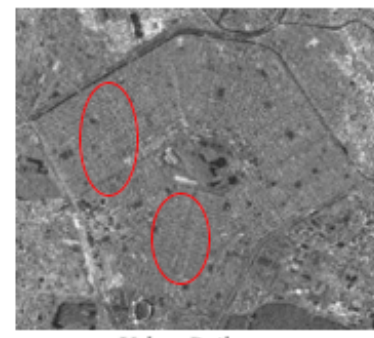

Urban Built-up

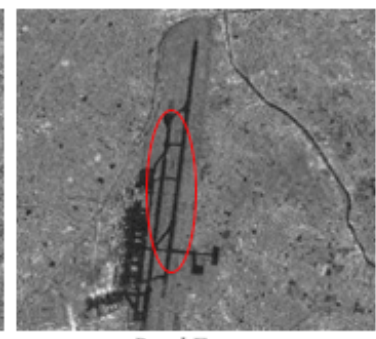

Road Feature

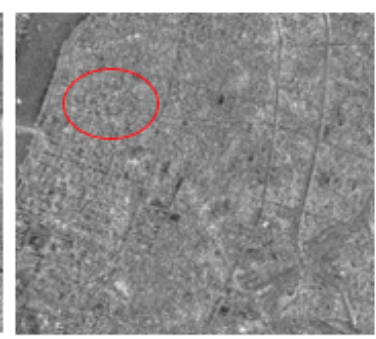

Sub-Urban

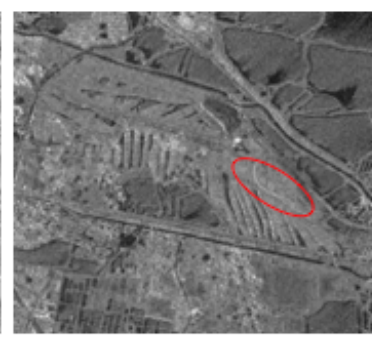

Crop Land

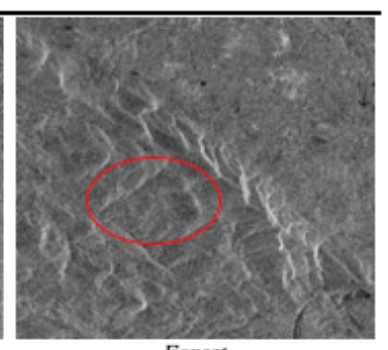

Forest

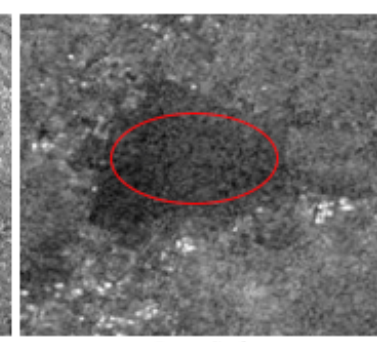

Bare Soil

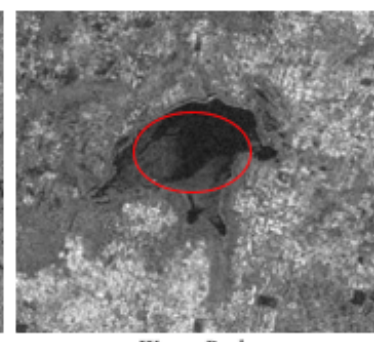

Water Body

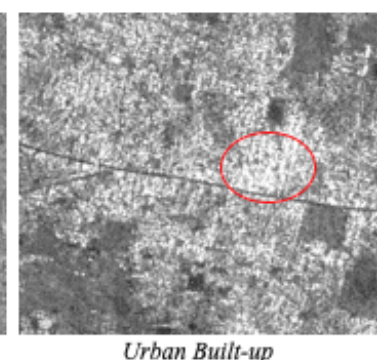

Urban Built-up

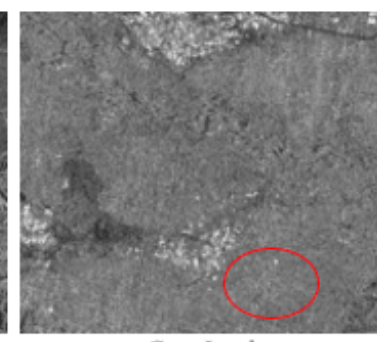

Crop Land

\section{Figure 3}

The visual representation of various LULC classes from NovaSAR-1 (July-2019) data acquired on experimental sites 


\section{Chhattisgarh Site Maharashtra Site $\quad$ West Bengal Site $\quad$ Jharkhand Site}

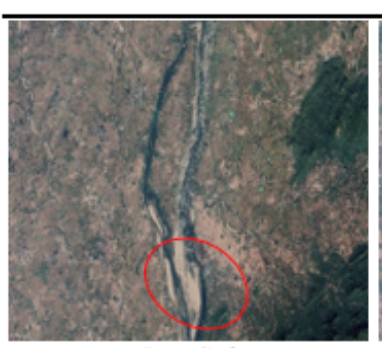

Bare Soil

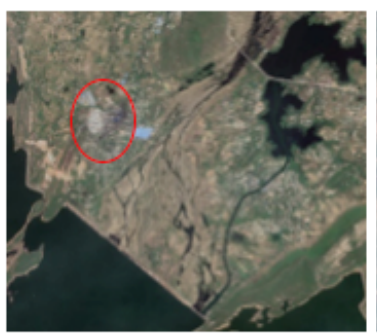

Urban Built-up

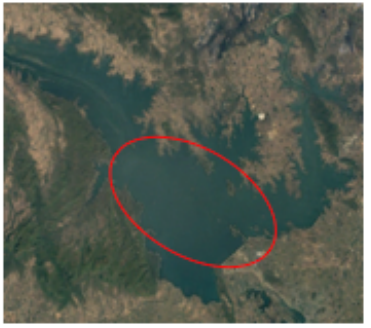

Turbid Water

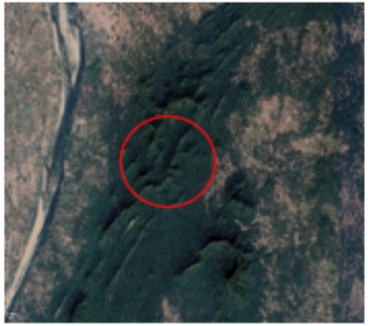

Forest

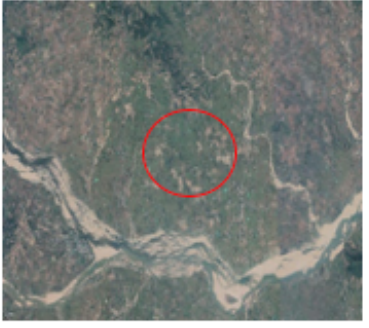

Crop Land

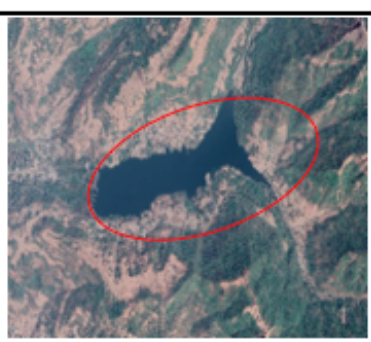

Turbid Water

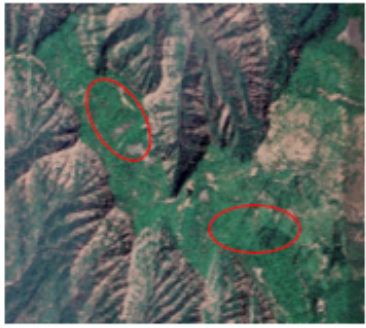

Forest

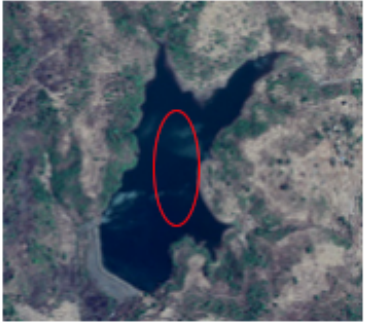

Smooth Water Surface

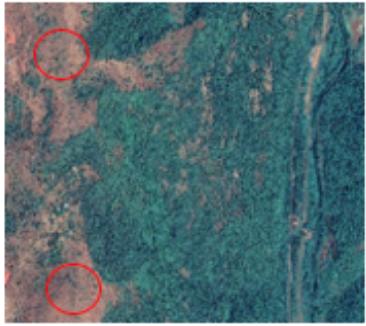

Crop Land

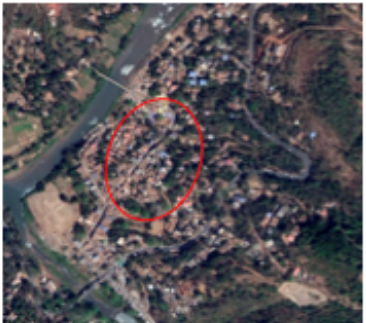

Sub-Urban

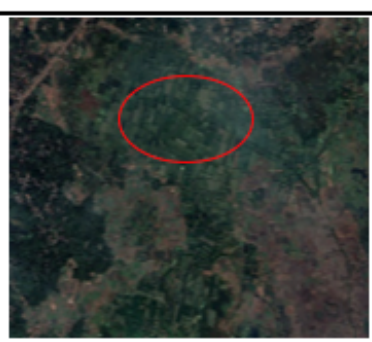

Swamp

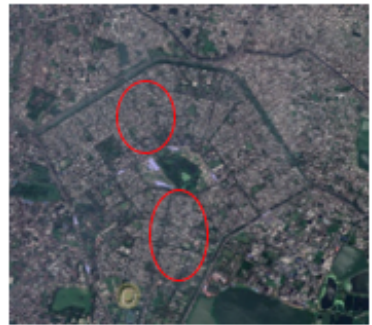

Urban Built-up

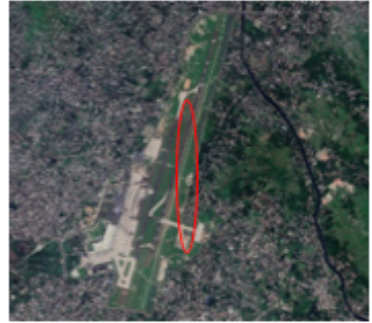

Road Feature

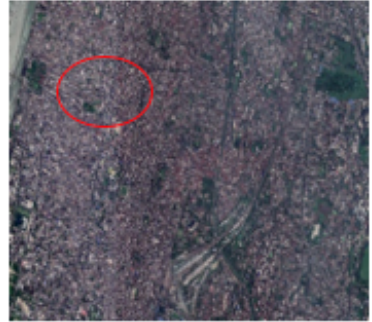

Sub-Urban

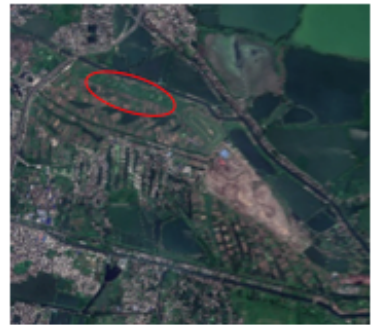

Crop Land

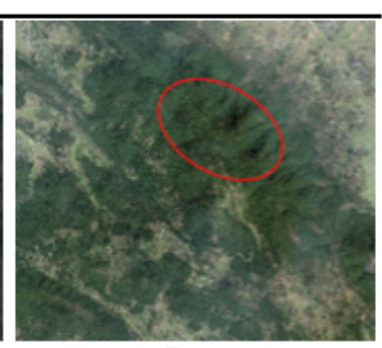

Forest

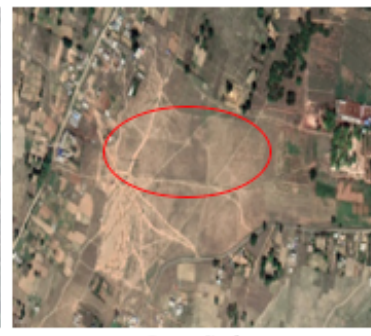

Bare Soil

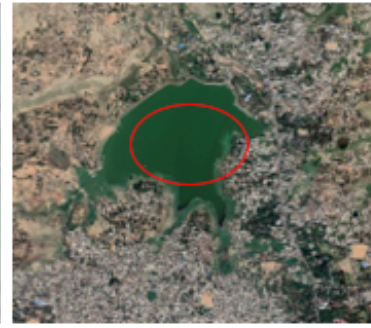

Water Body

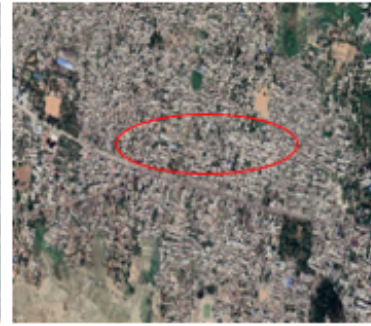

Urban Built-up

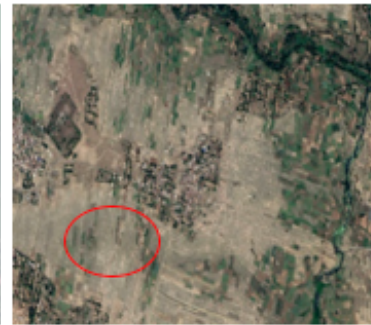

Crop Land

Figure 4

The visual representation of various LULC classes from Google Earth Images (July-2019) acquired on experimental sites corresponding to the sites shown in figure 3 . 


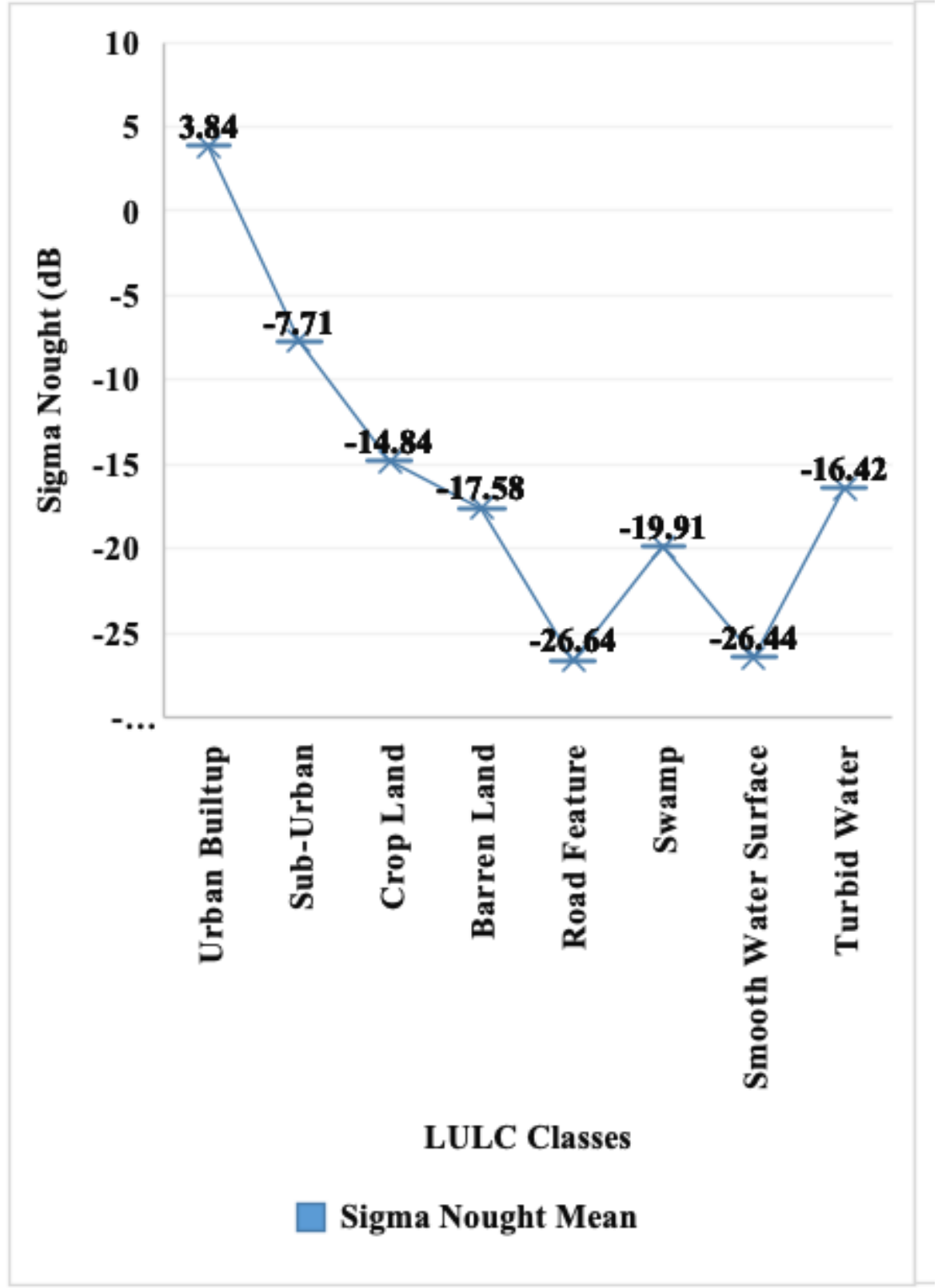

Figure 5

Mean $\sigma 囚$ Statistics for Different Classes (West Benga-1: Kolkata Site) 


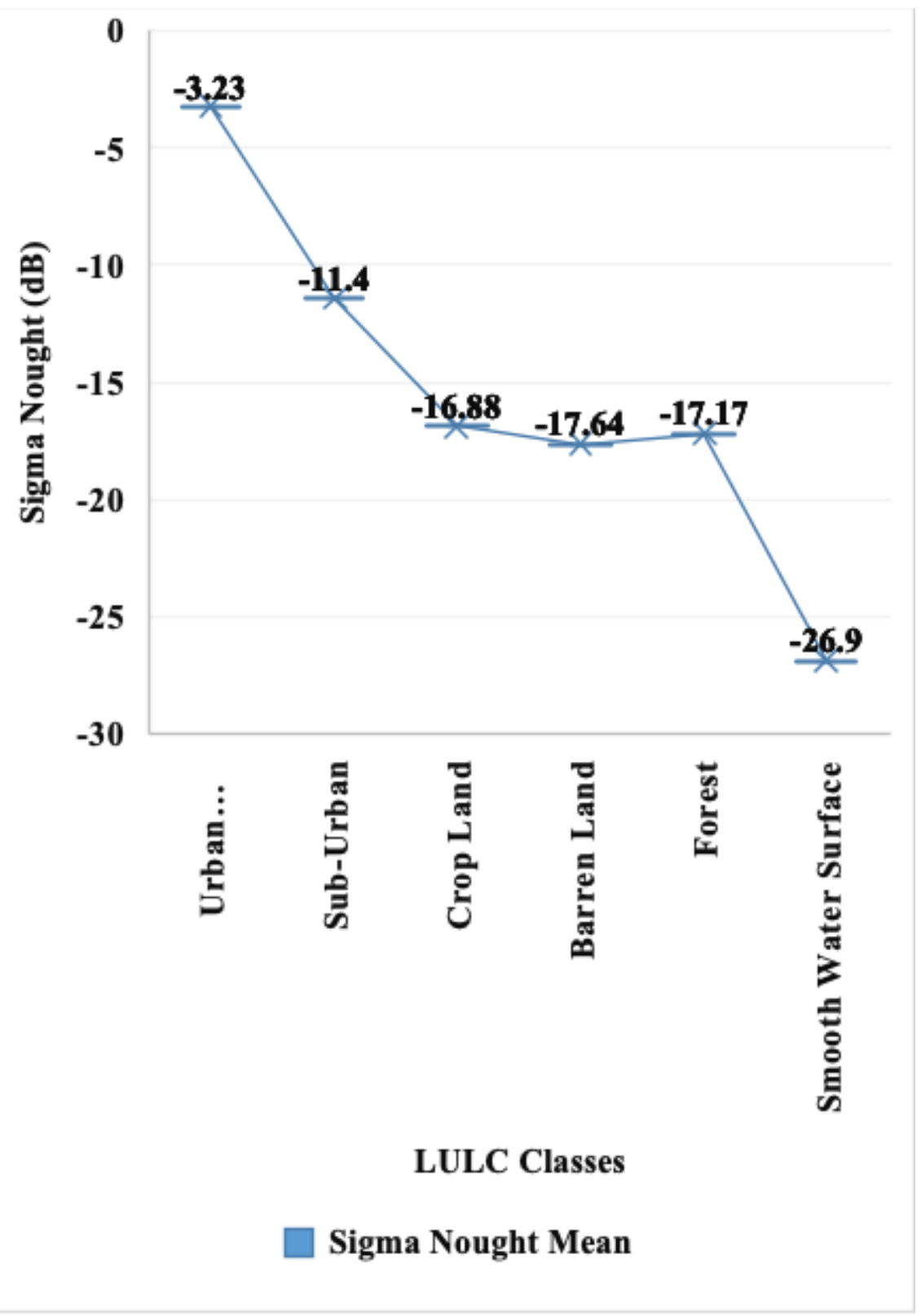

Figure 6

Mean $\sigma \otimes$ Statistics for Different Classes (Maharashtra Site) 


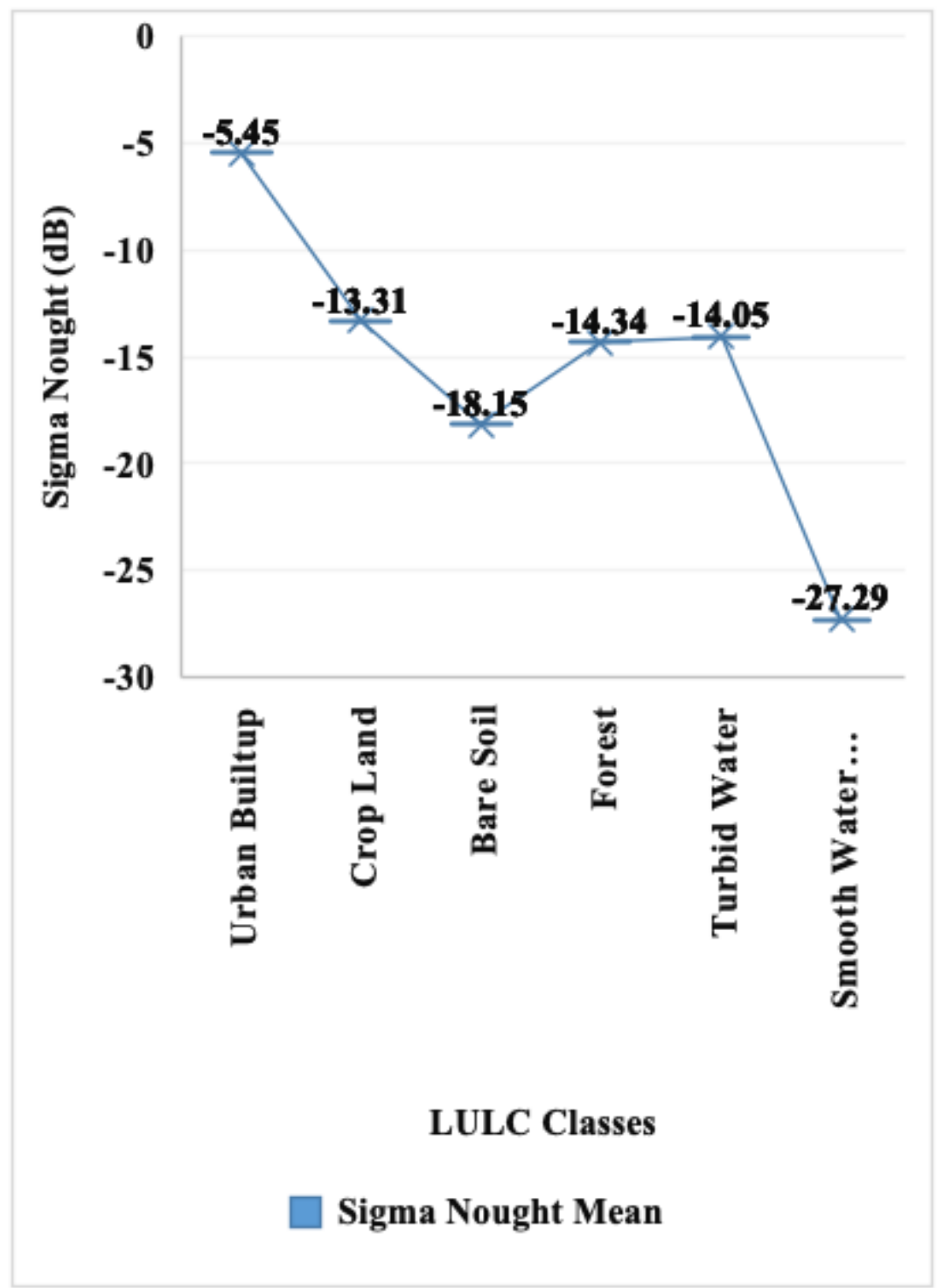

Figure 7

Mean $\sigma \otimes$ Statistics for Different Classes (Chhattisgarh Site) 


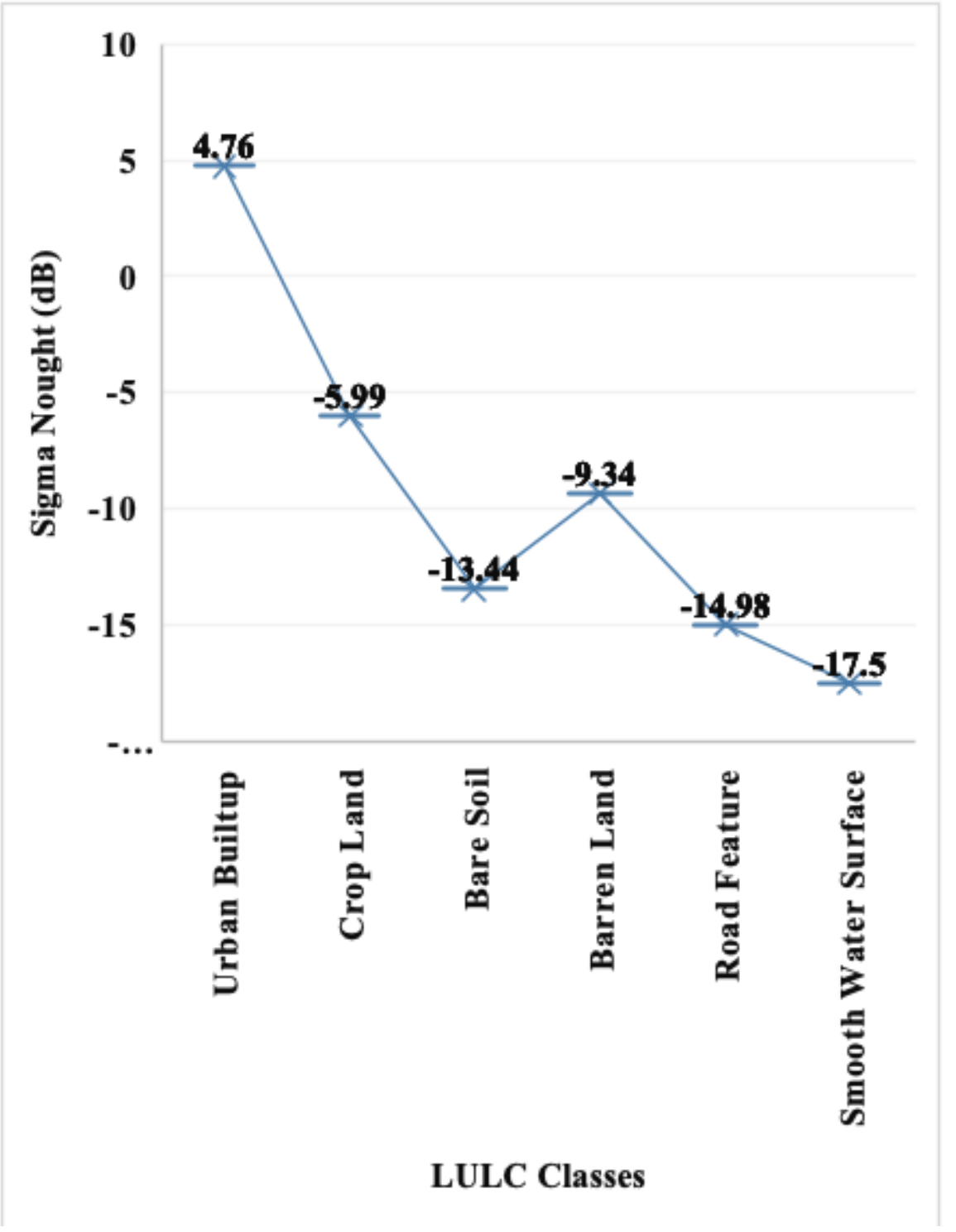

Figure 8

Mean $\sigma \rrbracket$ Statistics for Different Classes (Ranchi Site) 


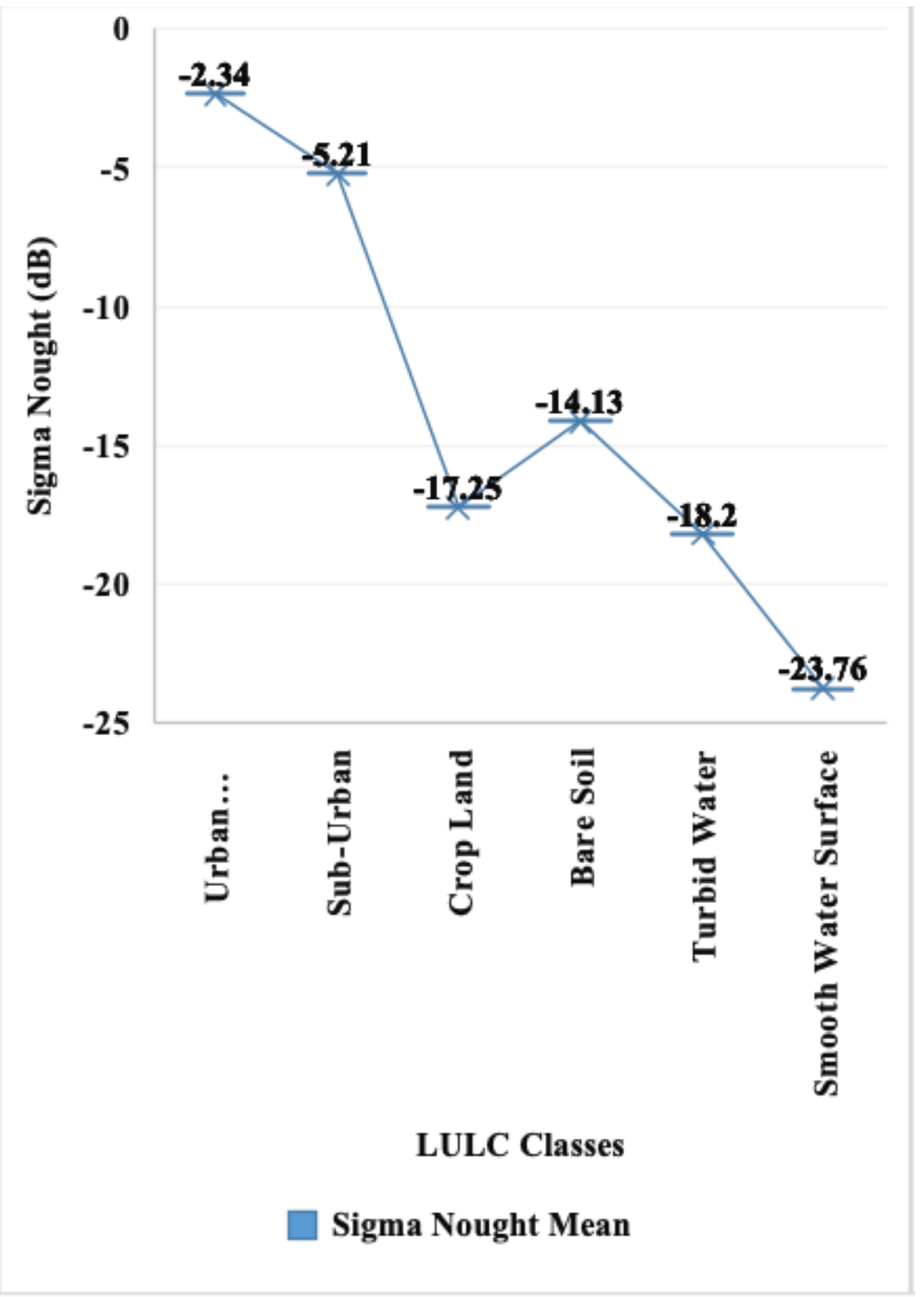

Figure 9

Mean $\sigma \otimes$ Statistics for Different Classes (West_Bengal-2 Site) 


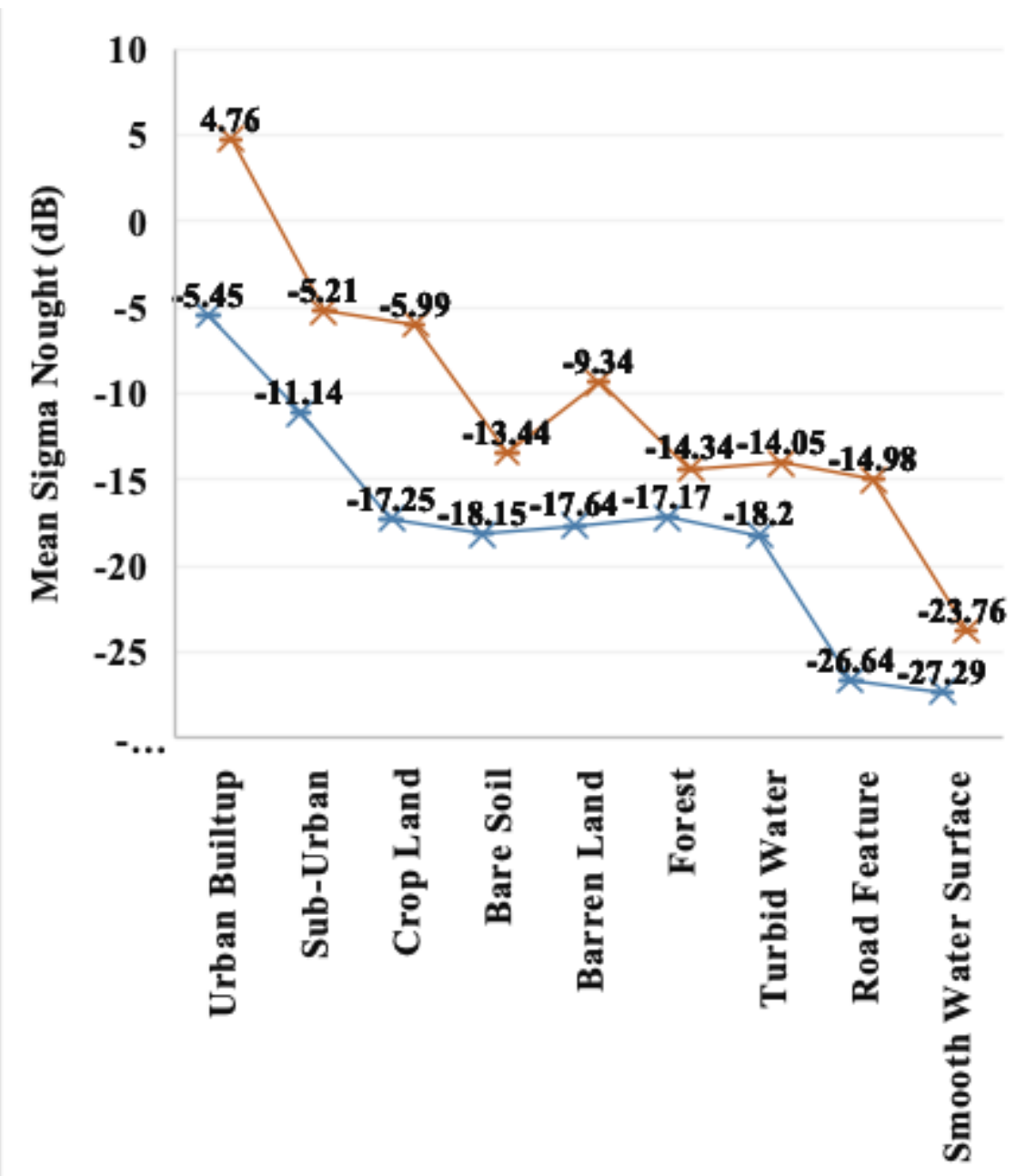

LULC Classes

Minimmum Mean $\sigma^{\circ}$ Value

Maximum Mean $\sigma^{\circ}$ Value

Figure 10

Graph depicting range (Minimum to Maximum) of Mean $\sigma^{\circ}$ Value of Different LULC for Various Experimental Sites. 


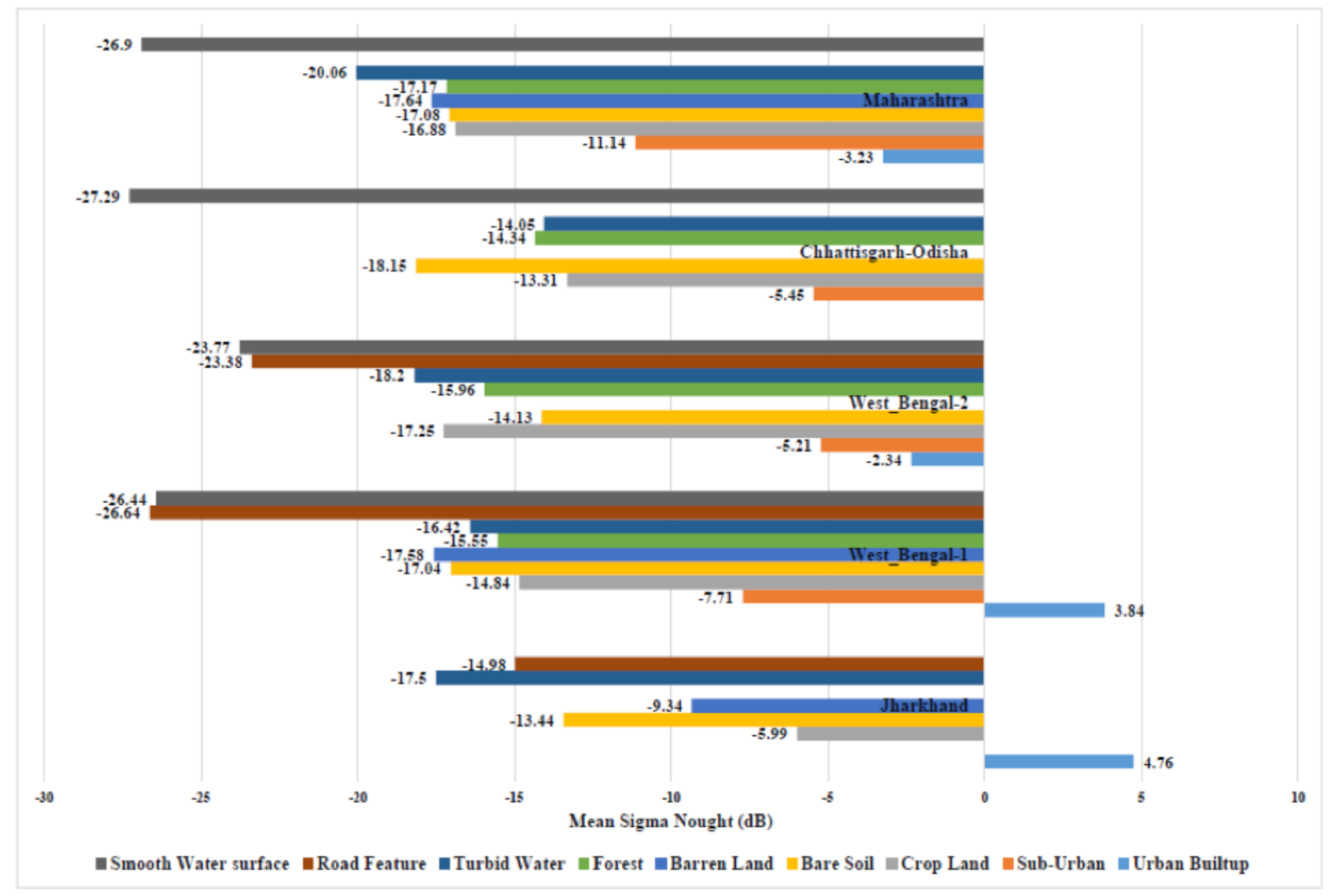

Figure 11

Comparative Mean $\sigma \rrbracket$ Analysis of Different Land-Covers for Different Experimental sites 


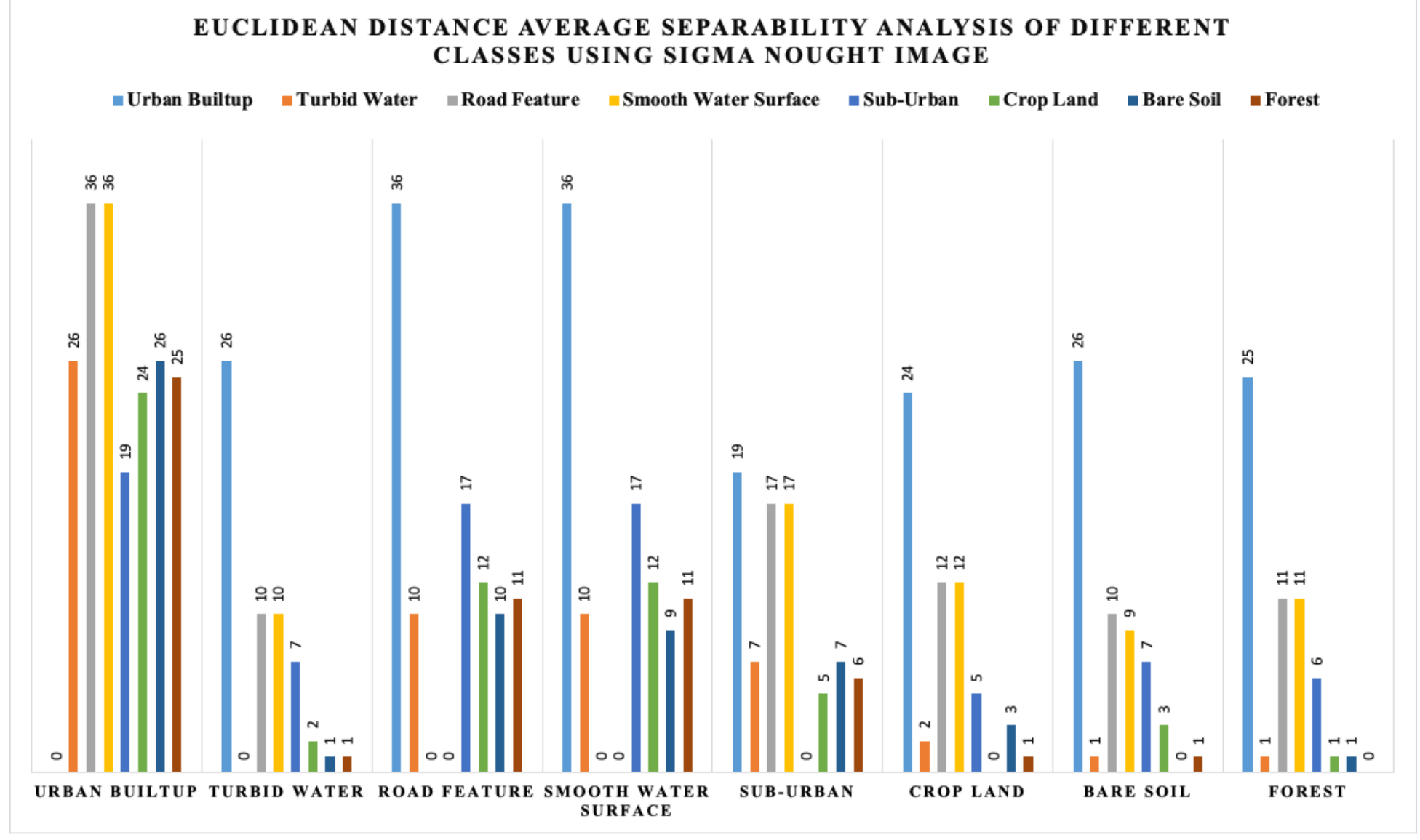

Figure 12

Euclidean Distance Average Separability Analysis of Different classes of Kolkata (West Bengal-1) Sigma Nought Image 
TRANSFORM DIVERGENCE AVERAGE SEPARABILITY ANALYSIS

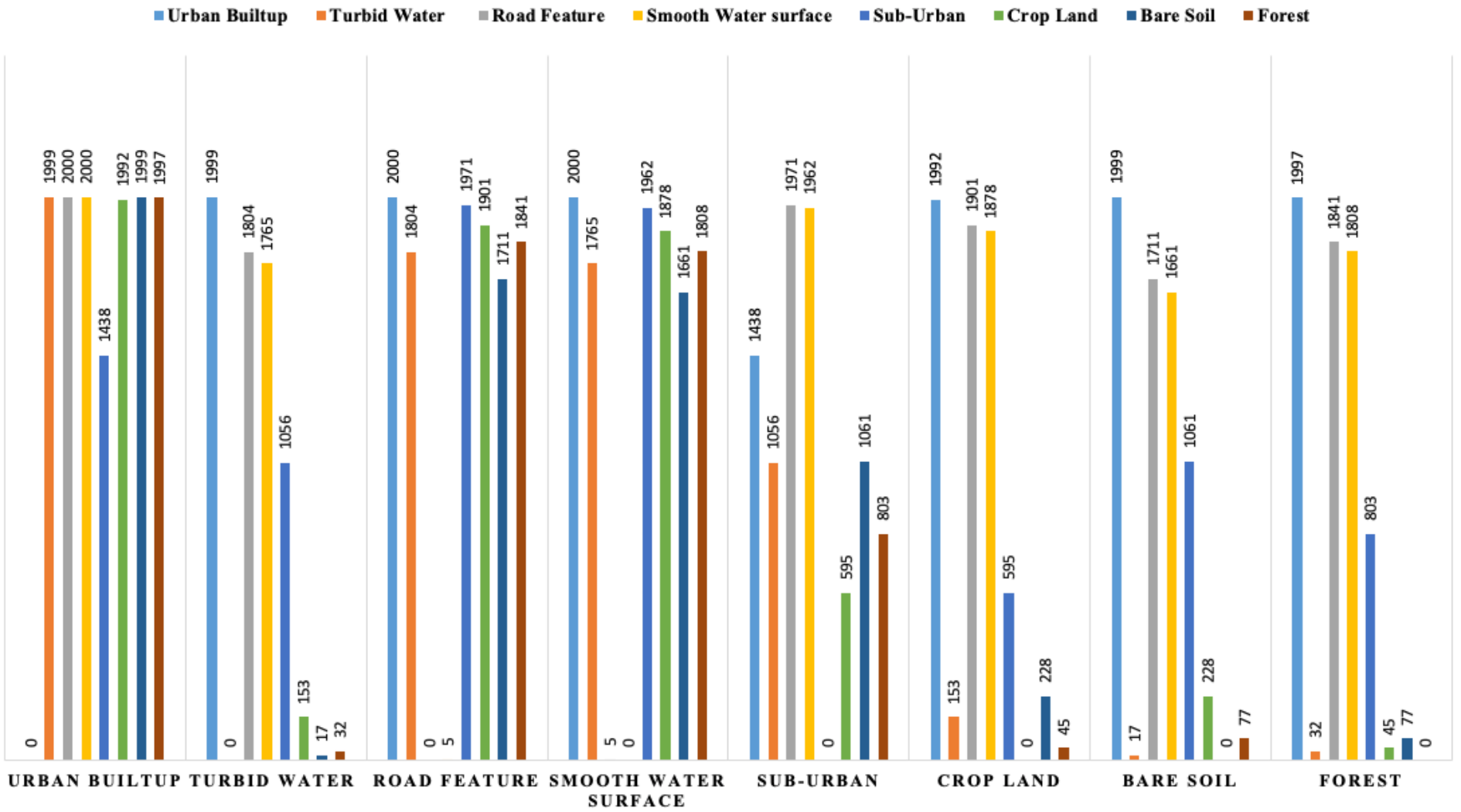

Figure 13

Transformed Divergence Average Separability Analysis of Different classes of Kolkata (West Bengal-1) Sigma Nought Image 


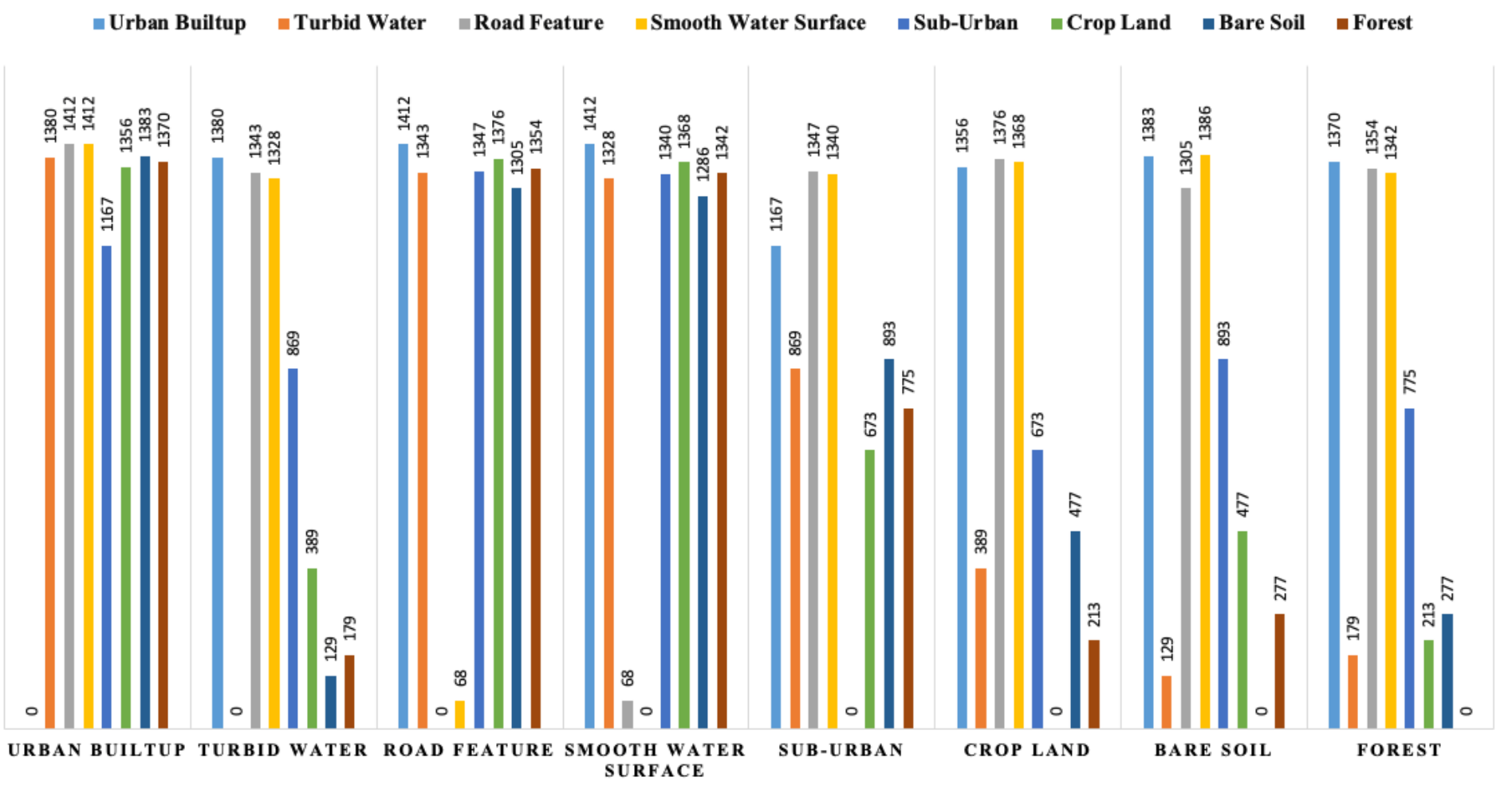

Figure 14

Jefferies-Matusita Average Separability Analysis of Different classes of Kolkata (West Bengal-1) Sigma Nought Image 


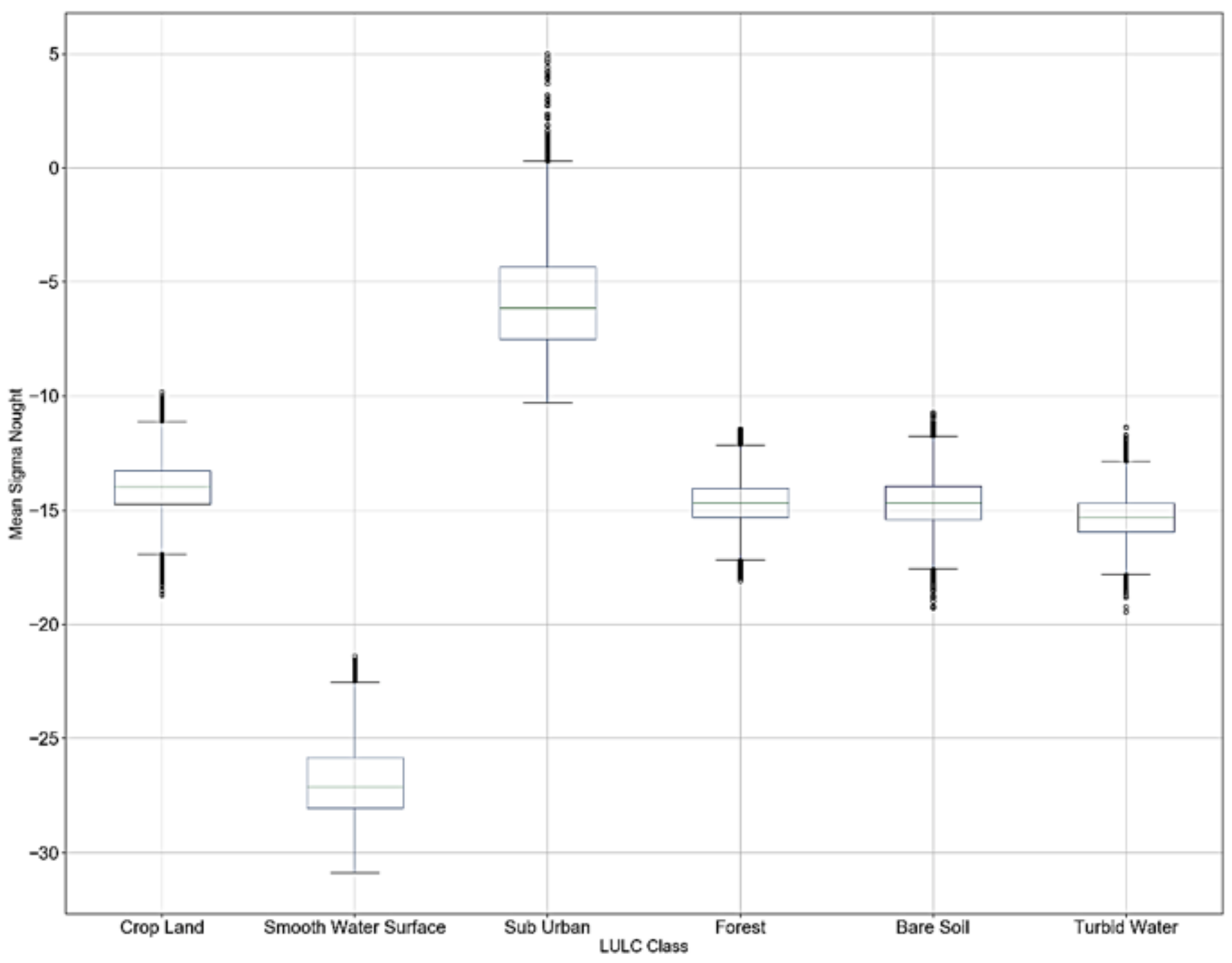

Figure 15

Box plot for Chhattisgarh LULC classes of Chhattisgarh experimental site. 


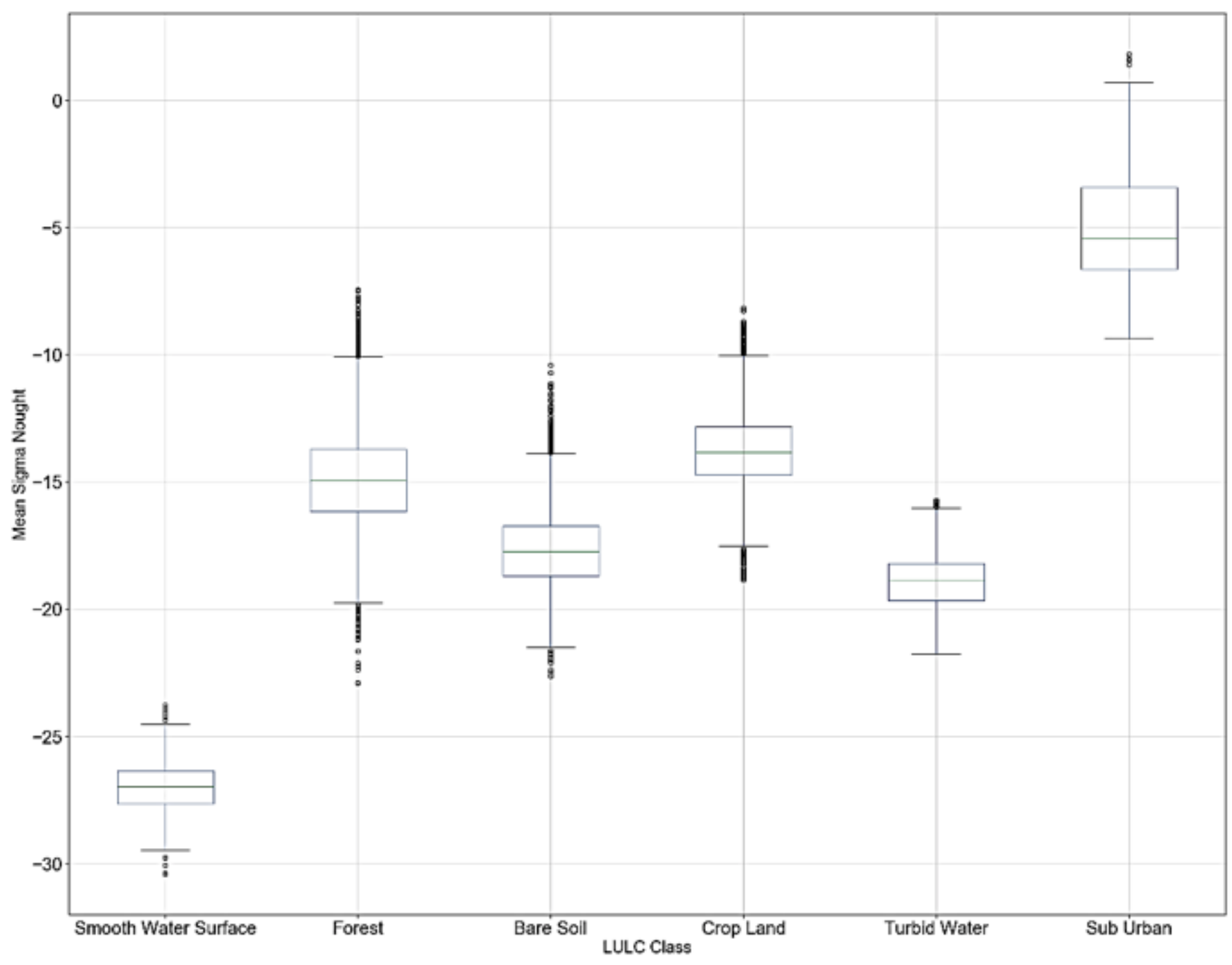

Figure 16

Box plot for LULC classes of Maharashtra Experimental site. 


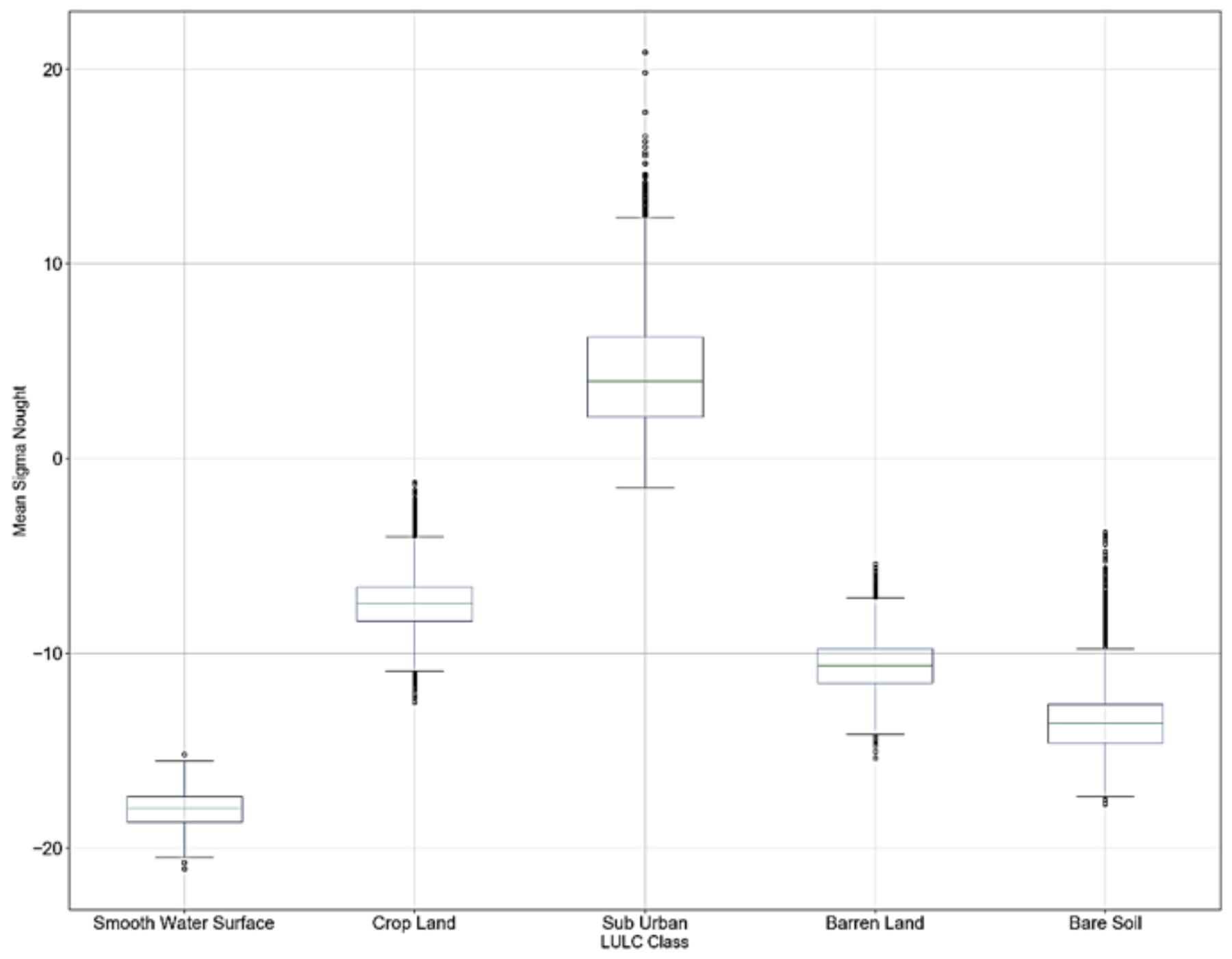

Figure 17

Box plot for LULC classes of Ranchi experimental site. 


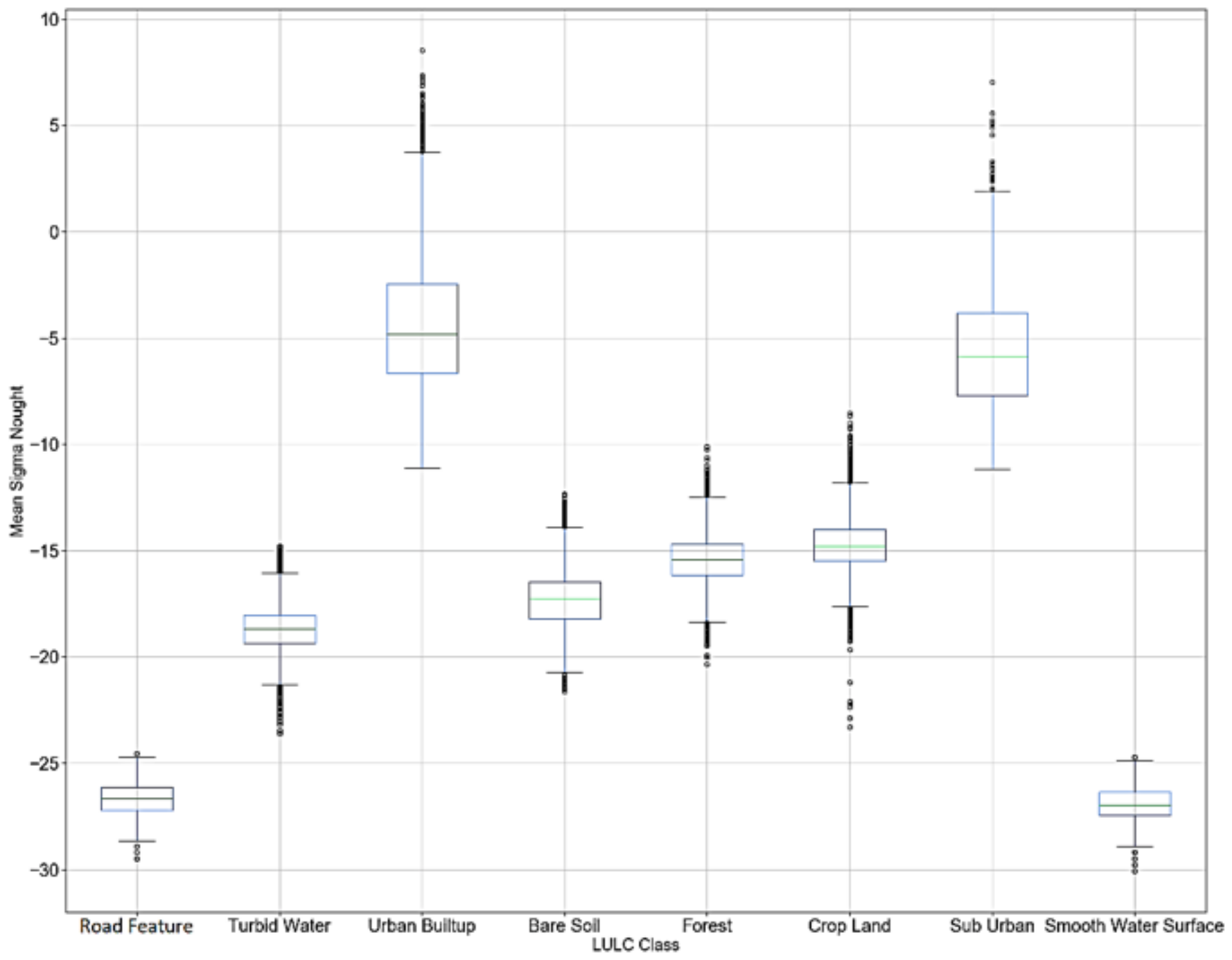

Figure 18

Box plot for LULC classes of West Bengal-1 experimental site. 